\title{
Suicide portrayal in the Canadian media: examining newspaper coverage of the popular Netflix series '13 Reasons Why'
}

Victoria Carmichael and Rob Whitley

\begin{abstract}
Background: Evidence suggests that the media can influence societal attitudes and beliefs to various social issues. This influence is especially strong for mental health issues, particularly suicide. As such, the aim of this study is to systematically examine Canadian newspaper coverage of the popular fictional Netflix series 13 Reasons Why, wherein the lead character dies by suicide in the final episode.

Methods: Articles mentioning the series were systematically collected from best-selling Canadian newspapers in the three-month period following series release (April-June 2017). Articles were coded for adherence to key best practice recommendations on how to sensitively report suicide. Frequency counts and proportions were produced. An inductive qualitative thematic analysis was then undertaken to identify common themes within the articles.
\end{abstract}

Results: A total of 71 articles met study inclusion criteria. The majority of articles did not mention the suicide method (88.7\%) and did not use stigmatizing language such as 'commit suicide' (84.5\%). Almost half of the articles linked suicide to wider social issues (43.7\%) or quoted a mental health professional (45.1\%). $25 \%$ included information telling others considering suicide where to get help. Our qualitative analysis indicated that articles simultaneously praised and criticized the series. It was praised for (i) promoting dialogue and discussion about youth suicide; (ii) raising awareness of youth suicide issues; (iii) shining a spotlight on wider social issues that may affect suicide. It was criticized for (i) glorifying suicide, (ii) harmfully impacting young viewers; (iii) prompting pushback from educators and schools.

Conclusions: Newspaper coverage of ' 13 Reasons Why' generally adhered to core best practice media recommendations, and sensitively discussed suicide from various angles, prompting productive discussion and dialogue about youth suicide. These findings suggest that the media can be an ally in promoting dialogue and raising awareness of important public health issues such as suicide.

Keywords: Newspaper, Suicide, Youth, Canada, Media, Mental health, Contagion, 13 reasons why, Mixedmethods, Stigma

\footnotetext{
* Correspondence: robert.whitley@mcgill.ca

Department of Psychiatry, Douglas Mental Health University Institute, McGill

University, 6875 LaSalle Blvd, Montreal, QC H4H 1R3, Canada
}

(c) The Author(s). 2018 Open Access This article is distributed under the terms of the Creative Commons Attribution 4.0 International License (http://creativecommons.org/licenses/by/4.0/), which permits unrestricted use, distribution, and reproduction in any medium, provided you give appropriate credit to the original author(s) and the source, provide a link to the Creative Commons license, and indicate if changes were made. The Creative Commons Public Domain Dedication waiver (http://creativecommons.org/publicdomain/zero/1.0/) applies to the data made available in this article, unless otherwise stated. 


\section{Background}

Suicide remains a serious public health issue across the world [1], and is a leading cause of premature mortality in high-income countries such as the United States [2], Australia [3] and the United Kingdom [4]. In Canada, around 4000 people die by suicide each year, a rate of 11.5 per 100,000 [5]. This translates into roughly 70 Canadian deaths by suicide per week. Certain groups are more likely to die by suicide; the suicide rate for men is three to four times higher than for women [5], and Indigenous peoples are six to eleven times more likely to die by suicide than the general Canadian population [6].

The highest rates of suicide are seen in people aged 40 to 60 . That said, young people also have high rates of suicide. In fact, suicide is the leading cause of death among people aged 10-24, and in 2009 accounted for nearly one quarter (23\%) of all deaths for Canadian youth aged 15 to 19 [5]. A study examining Canadian youth suicide rates between 1980 and 2008 found a significant increase in the suicide rates for females aged 10 to 19 [7].

Given this situation, governments across the world have attempted to address the issue of suicide. The Mental Health Commission of Canada (MHCC) published Canada's first national mental health strategy in 2012, which prioritized "promoting mental health and preventing mental illness and suicide". The MHCC devoted resources to positive collaboration with the media as part of its strategy, aiming to improve coverage of mental health and suicide issues [8].

This action was based on considerable research indicating that the media plays a major role in shaping public attitudes, beliefs and behaviours towards health and social issues, including suicide [9]. Indeed, critical examination of media coverage of health issues has become a common form of analysis (and intervention) in public health research, with studies examining issues such as Ebola [10], Creutzfeldt-Jakob disease [11], obesity [12], diabetes [13], regulation of antibiotics [14], cancer [15], social isolation [16], mental health [17-19] and suicide [20].

With regards to suicide, some studies indicate that the media can be a positive force, educating the community and raising awareness of important suicide-related issues such as social determinants, helplines and available treatments [20]. However, other studies suggest that some media still sensationalize and simplify issues surrounding suicide, which may lead to public misunderstandings and even suicide contagion [18].

Suicide contagion is a well-documented phenomenon whereby an increase in suicide and suicidal behaviour is observed following the suicide of a celebrity, peer or family member [21]. Some research indicates that repeated sensational and glorified media coverage of a suicide can lead to an increase in contagion behaviour, particularly if it describes suicide methods in detail [22, 23]. This is especially so if the suicide involves a celebrity or public figure [24]. Indeed, a recent study found a $10 \%$ increase in suicides in the U.S. in the months following Robin William's suicide, which was tentatively imputed to explicitly descriptive and sensational media coverage fueling 'copycat suicides' in the community [25].

In fact, some research shows a correlation between reporting on a suicide method and subsequent suicide by the said method [26]. Notably, evidence suggests that youth in particular are especially influenced by suicide coverage in the media, both real and fictional [27]. As such, the media can be a double-edged sword for suicide prevention. It can raise awareness and educate the public about underlying public health issues such as social determinants and available treatments; however, it may also contribute to suicide contagion.

Given this dual potentiality of the media, the MHCC recently funded the production of a short booklet containing evidence-based recommendations and best-practices for journalists reporting about mental health and suicide called Mindset [28]. This booklet was produced in collaboration with the Canadian Journalism Forum on Violence and Trauma and the Canadian Broadcasting Corporation, with input from senior academics familiar with the suicide prevention literature. Within Mindset, there are 14 recommendations to journalists for reporting suicide, such as 'do not describe the method used', 'do not use the word commit', 'do tell others considering suicide how they can get help' and 'do link to wider social issues' (see Additional file 1: Table S1).

\section{Reasons Why}

Thirteen Reasons Why is a popular fictional Netflix show chronicling the lives of a group of American teenagers. The lead character, Hannah Baker, experiences a number of acute and chronic stressors such as rape and bullying which lead her to take her own life in a graphic and bloody scene in the final episode. The series was released on March 312017 and quickly became one of the most watched series on the popular streaming platform. Indeed, it was the third most popular show on the platform across 32 countries in 2017 [29].

Beyond attracting a wide viewership, the series started a national conversation about suicide. It also 
prompted much media and research interest on the impact of the program and the issue of youth suicide. For instance, a just-released study found that internet searches related to suicide increased by $19 \%$ in the three-week period following the release of the series, including searches for phrases such as "how to commit suicide", "teen suicide" and "suicide hotline numbers" [30].

Given this situation, the overall aim of this study is to systematically examine Canadian newspaper coverage of the series 13 Reasons Why. The primary objective is to assess the content of media coverage of 13 Reasons Why in Canadian newspapers, examining fidelity to core suicide reporting recommendations detailed in Mindset. The secondary objective is to identify common themes and issues discussed in these articles, especially as related to youth suicide.

\section{Methods \\ Sampling}

This study is part of a wider 8-year longitudinal study examining trends in media coverage of mental illness in Canadian media $[18,19]$. The data for this study was obtained using FP Infomart. This is a comprehensive on-line depository of newspaper articles, television clips and social media posts, storing full-text news articles from over 1800 Canadian and international news sources from 1985 onwards [31]. FP Infomart is updated daily, and subscribers can search and retrieve media pieces containing key words within a specific date range. FP Infomart has been called 'Canada's leading media monitoring service' [32], and is widely used in media and health research due to its ability to quickly access full-text news articles from a comprehensive list of sources [33-35].

For the present study, articles mentioning the terms 'Thirteen/13 Reasons Why' were collected from over 20 Canadian news sources stored in the FP Infomart database. These included Canada's most widely-read national newspapers, such as the Globe and Mail and the National Post, as well as best-selling regional newspapers which are popular in their local communities, such as the Toronto Star and the Vancouver Sun [36]. We also included two popular online news sources: CBC.ca News and metronews.ca. A complete list of the news sources included in this study, as well as readership figures and rankings, are given in Table 1.

We searched for articles in the three-month period following the series' release on Netflix (April 12017 to June 30 2017). Three months was selected as a date range, as media research suggests that the 24/7 news cycle is currently very rapid, with most news
Table 1 List of newspapers and online news included in sample by circulation [36]

\begin{tabular}{|c|c|c|}
\hline Rank & Title of newspaper & Average daily circulation \\
\hline 1. & The Globe and Mail & 323,133 \\
\hline 2. & Toronto Star & 308,881 \\
\hline 3. & Maclean's & 225,963 \\
\hline 4. & National Post & 183,111 \\
\hline 5. & Vancouver Sun & 141,246 \\
\hline 6. & Toronto Sun & 134,266 \\
\hline 7. & The Province & 124,377 \\
\hline 8. & Hamilton Spectator & 113,963 \\
\hline 9. & Calgary Herald & 113,850 \\
\hline 10. & Ottawa Citizen & 105,614 \\
\hline 11. & Winnipeg Free Press & 104,909 \\
\hline 12. & Edmonton Journal & 99,044 \\
\hline 13. & The Gazette (Montreal) & 88,654 \\
\hline 14. & The Record & 56,595 \\
\hline 15. & Winnipeg Sun & 56,211 \\
\hline 16. & Times Colonist & 55,152 \\
\hline 17. & Windsor Star & 54,119 \\
\hline 18. & Calgary Sun & 43,734 \\
\hline 19. & The Saskatoon StarPhoenix & 43,593 \\
\hline 20. & Edmonton Sun & 39,918 \\
\hline 21. & Ottawa Sun & 39,270 \\
\hline 22. & The Leader-Post & 36,541 \\
\hline 23. & The Telegram (St. John's) & 31,823 \\
\hline 24. & The Daily Gleaner & 16,102 \\
\hline 25. & CBC.CA News ${ }^{a}$ & $\mathrm{n} / \mathrm{a}$ \\
\hline 26. & Metronews.ca ${ }^{a}$ & $\mathrm{n} / \mathrm{a}$ \\
\hline
\end{tabular}

$n / a$ Not available

${ }^{\text {aT }}$ These two are online news sources and so there is no daily circulation numbers available

articles about an event published in the days and immediate weeks following the event [37]. Indeed, other research indicates that in this era of viral news, the newsworthiness of an event decreases swiftly after the said event, to be quickly replaced by other news $[38,39]$. As such, three months is a relatively lengthy time-period when analyzing news about an event in a fictional Netflix series.

\section{Procedures}

All articles were retrieved by the first author who was closely supervised in the process by the principal investigator (the last author). Articles were excluded from analysis if the article only made a passing or incidental reference to 13 Reasons Why. For example, 
articles solely about the actors from the series were excluded. This strategy allowed us to focus our attention on articles related to coverage of the series itself. Articles were also excluded if they were exact duplicates of earlier online or print versions.

The articles were then coded for the presence or absence of five key variables. These key variables were derived from core recommendations from Mindset, as well as questions from our wider longitudinal study. These variables were:

1. Does the article link suicide to broader social issues? (yes/no)

2. Does the article include a quote from a mental health expert? (yes/no)

3. Does the article go into details about the method of suicide used? (yes/no)

4. Does the article use the word "commit" when discussing suicide? (yes/no)

5. Does the article include information about where to get help? (yes/no)

Codes were entered into Excel for data storage and analysis. Frequency counts and proportions were produced for each variable.

We did not include every single one of the Mindset recommendations in our analysis, as many of them were not applicable, given that the suicide of Hannah Baker was fictional, not an actual suicide. For instance, "do respect the privacy and grief of family or other survivors" and "do not jump to conclusions. The reasons why people kill themselves are usually complex" are not applicable due to the fictional nature of the suicide. Similarly, other recommendations such as "do consider whether this particular death is newsworthy" and "do not shy away from writing about suicide. The more taboo, the more the myth" were not measured as they are not content recommendations, and by definition every single article would be coded positively for both of these recommendations. As such, we selected variables that were most relevant and have been linked most frequently in the scientific literature to suicide contagion and suicide prevention, as outlined in the introduction [21-26].

\section{Qualitative analysis}

We then conducted an inductive qualitative thematic analysis of the articles. As this was an inductive analysis, no pre-existing framework was used to code and categorize the data. Instead, we followed standard procedure of identifying and labelling common themes that regularly appeared in the newspaper articles through systematic step-by-step procedures [40-42]. More specifically, both authors read all of the articles and engaged in independent 'open-coding, sometimes referred to as processes of 'immersion' and 'mapping' in the qualitative literature [42]. This involved labelling portions of the articles (or sometimes even whole articles) with codes that summarized key content in the articles. The authors then met to discuss their coding and mapping efforts, paying particular attention to codes that reappeared regularly across the data set in both authors' independent analysis. At this stage, the authors consensually created a list of themes and sub-themes that best described transversal patterns in the data [41]. The first author then engaged in a second-round of supervised 'focused coding', utilizing the thematic framework to formally enumerate the presence or absence of the identified themes and sub-themes in each article $[40,42]$.

The themes and sub-themes presented in the results represent this framework, and were agreed upon consensually by both authors as a faithful summary of the common themes transversal across the data-set. This process follows recommended procedure for maintaining rigour in qualitative research through multiple coding, close teamwork and supervision, and systematic step-by-step processes of analysis [42]. Data for this study was a collection of short media articles, rather than lengthy in-depth interview or focus group transcripts. As such, the analysis was done manually rather than with computer-assisted qualitative data analysis software.

\section{Results}

The retrieval strategy produced a grand total of 147 articles. This was reduced to 109 articles as 38 articles were excluded for making only passing or incidental reference to ' 13 Reasons Why'. Another 38 articles were subsequently excluded as duplicates during the coding process. This led to a total of 71 usable articles being included in analysis. All 71 articles are listed in Appendix. The overall proportions and percentages of key variables are presented in Table 2.

Frequency counts indicate that articles generally adhered to the core variables selected to assess content. For instance, out of the 71 articles, 60 $(84.5 \%)$ did not use the word 'commit' when discussing Hannah's suicide and 63 (88.7\%) did not go into detail about the method used. Further, $45.1 \%$ of articles quoted a mental health professional while $43.7 \%$ linked Hannah's suicide to wider social issues. However, only 18 articles (25.4\%) 
Table 2 Basic description of newspaper variables

\begin{tabular}{lll}
\hline Variables & Number of articles & Percent $(N=71)$ \\
\hline Link to wider social issues & 31 & 43.7 \\
Mental health expert quoted & 32 & 45.1 \\
Method discussed & 8 & 11.3 \\
Use of "commit" & 11 & 15.5 \\
Tell others how they can get help & 18 & 25.4 \\
\hline
\end{tabular}

included information about where to get help for those considering suicide.

The qualitative analysis indicated that articles tended to include praise and criticism of the series in equal measure. Sub-analysis indicated that when praising the series, articles commonly mentioned that it was useful in (i) promoting dialogue and discussion about youth suicide, (ii) raising awareness for youth suicide prevention and (iii) shining a spotlight on wider social issues that may affect suicide. In contrast, when criticizing the series, articles commonly mentioned that it (i) glorified suicide, (ii) could harmfully impact or trigger impressionable young viewers and (iii) rightfully led to pushback from educators and schools. The frequency counts and percentages of themes are presented in Table 3.

\section{Praise of the series}

A total of 53 articles (74.6\%) contained praise of the series for promoting dialogue and discussion about youth suicide. Many noted that the series created a starting point for discussion about difficult topics, particularly relating to youth mental health and suicide. For example, one article stated that "the show has prompted thousands of young people to talk about the issues of bullying, assault and suicide that they see in their own lives" (A70) and "this show is

Table 3 Themes extracted from qualitative analysis

\begin{tabular}{lll}
\hline & $\begin{array}{l}\text { Number of } \\
\text { articles }\end{array}$ & $\begin{array}{l}\text { Percent } \\
(\mathrm{N}=71)\end{array}$ \\
\hline Praise & 53 & 74.6 \\
$\quad$ Promoting dialogue and discussion & 39 & 54.9 \\
Raising awareness for suicide prevention & 38 & 53.5 \\
Shining a spotlight on wider social issues & & \\
Critiques & 57 & 80.3 \\
Glorification of suicide & 43 & 60.6 \\
Potentially harmful impact on viewers & 39 & 54.9 \\
Pushback from educators and schools & 39 & \\
\hline
\end{tabular}

letting the genie out of the bottle. Mental health concerns are being talked about like never before" (A24). Others remarked more generally on the need for, and importance of, having an open discussion about mental health and suicide in light of the series, writing that the series has led to "hope and belief that the dialogue on and around 13 Reasons Why will create the pro-active dialogue on suicide that we, young and old alike, need so badly..." (A36). Similarly, another article mentioned that the series is "shining light on a tragic problem [mental health and suicide]" and that it is "worth talking about" (A60).

Likewise, 39 articles (54.9\%) contained praise of the series for raising awareness about youth suicide issues, especially prevention. Many used the series as an opportunity to educate readers about youth suicide, presenting informative facts and figures. For example, one article informed readers that "the suicide rate among girls has increased by $38 \%$ over the past 10 years" (A60). Others also provided readers with tips for suicide prevention, placing a strong emphasis on social support, outreach and help-seeking behaviour. This included quoting mental health professionals about how to approach someone who is suicidal. For example, one quoted Mara Grunau, executive director of the Centre for Suicide Prevention, saying (A69):

'If you're ever worried about a friend or family member, if somebody in your world is considering suicide, ask them directly...If they answer yes, don't panic, don't try to solve problems, don't be like the guidance counsellor in the Netflix series. Actively listen, affirm them, be there for them and connect them to help.'

Others provided readers with mental health resources available in their local communities (including on-line resources) or a suicide hotline number at the end of the article.

Finally, much of the media coverage used the series to shine a spotlight on various social issues related to suicide experienced by youth today. In fact, 38 articles $(53.5 \%)$ highlighted the positive depiction of relevant social issues in the series, remarking that "13 Reasons speaks to young people frankly about difficult contemporary issues like cyberbullying, sexual harassment, date rape and drug use" (A24). Some articles framed this depiction of social issues as a silver lining of the series. One article, for example, wrote how "Shayna King, a 14-year-old student at Westdale Secondary School, says while the show was 'upsetting 
and dark,' it tackles realistic subject matter that could help parents and educators understand teenagers" (A16). Another noted that although the series has serious flaws, "it does show the ways schools fail to deal with issues like bullying, mental health, rape culture and sexual violence" (A40).

\section{Criticism of the series}

A total of 57 articles (80.3\%) criticized the graphic portrayal of Hannah Baker's suicide, sometimes noting that this was gratuitously explicit. For example, one article noted that the suicide is "graphic and it is brutal...The wrist-slashing seems gratuitous and unnecessary...That scene -and the series more generally- breaks all the rules" (A24). Other articles argued that the whole storyline glorifies and romanticizes suicide. Emblematic examples included "she's getting more quote-unquote attention than when she was alive" (A45) and "self-harm can make an unpopular girl the centre of attention" (A67). Many also critiqued the show as overly simplistic and narrow, portraying suicide as a way to "exact revenge" (A45, A67, A24). Some framed this focus on revenge as a failed opportunity to discuss mental illness and the role that it can play in suicide, writing that "another problem with the show is that it uses a suicide revenge plot instead of addressing the mental illness that caused it" (A44).

Linked to the above, 43 articles (60.6\%) highlighted how the series could be damaging for vulnerable youth. The vast majority of these articles focused on the danger of contagion associated with the graphic and detailed portrayal of suicide. Indeed, a common narrative that emerged was that the show could be a potential trigger for suicidal thoughts and actions in vulnerable youth. For example, one article remarked that the series makes suicide look "quick", "relaxing" and "even provides a how-to", which "for teens who are actually contemplating suicide, it's dangerous" (A44). Others described an increase in suicide threats and hospitalizations among youth which was linked to the series, referring to this as the "Thirteen Reasons Why effect" (A11). One article noted concerningly that "Calls to a Hamilton crisis line have tripled in recent months and those in the mental health field say some of that is caused by the Netflix drama 13 Reasons Why" (A45). Another described a specific case where "a 12-year-old girl who had been secretly watching the show "was having trouble going to school. She was having panic attacks... [she] made a suicide threat...the show had been a trigger for her"' (A68).
Finally, much of the media coverage focused on pushback from educators and schools across Canada in response to the series, with 39 articles (54.9\%) of discussing this pushback. This included describing the actions taken by educators aimed at preventing discussion and use of the series in schools. Some articles featured letters from school administrators which prohibited students from talking about the show during school hours, noting that "Students at an Edmonton elementary school have been ordered to refrain from discussion about 13 Reasons Why" (A15). Others remarked how teachers have been discouraged from using the show as an educational tool or talking about it with students, writing "Ontario educators are currently being advised not to use the series in classrooms, and not to initiate conversations about the show unless first approached by students" (A08).

\section{Discussion}

The key finding of this study is that Canadian newspapers generally adhered to core recommendations on reporting suicide when discussing 13 Reasons Why. Journalists overwhelmingly avoided the word 'commit', and perhaps most importantly, very rarely went into detail about the method used by Hannah Baker. Likewise, almost half of the articles linked Hannah's suicide to wider social issues (43.7\%) and quoted a mental health expert (45.1\%). These results could indicate a pattern of responsible reporting; many journalists used the series as an opportunity to raise awareness of social determinants and suicide prevention.

Nonetheless, there is room for some improvement. Just over half of the articles did not link suicide to wider social issues, nor included a quote from a mental health expert. These are important omissions, as such information could help raise awareness about social determinants and prevention strategies. Further, eight articles (11.3\%) described the suicide method used in the series. Though this is a small number, it is troubling as research shows a correlation between media reporting on a suicide method and contagion suicide by such method [26].

Further, only around a quarter of articles (25.4\%) included information about where to get help; such as a suicide hotline number, online resources or service listing for those considering suicide. This is a missed opportunity given the possibility of youth suicide contagion related to media portrayals [27]. It also stands in contrast to Mindset best practice recommendations which suggest providing information about available resources or crisis hotlines when 
reporting suicide, which could help those in distress to seek help.

The other key finding is that Canadian journalists had ambivalent opinions about the series, and its implications for viewers and society as a whole. This ambivalence parallels a wider societal discourse over the best approach to suicide prevention; action or silence. In other words, is it better to talk or to not talk about suicide? On the one hand, some research suggests that people prefer not to talk about suicide out of fear that it could lead to contagion and suicidality [43]. On the other hand, other research shows that awareness and discussion about suicide may actually reduce suicide ideation and encourage help-seeking behaviour [44].

Many experts square this circle by calling for greater discussion of suicide issues, while simultaneously advocating for responsible media reporting of suicide [28]. This is especially important given the pervasiveness of social media in the lives of youth, where information (and misinformation) easily spreads across networks and into users' lives [45]. As such, sensitive and accurate reporting about suicide by the mainstream media could act as a counter-balance or corrective to (mis)information shared on social media. Indeed, there is a need for future research investigating the portrayal of suicide on social media and its impact on users.

Our analysis suggested that Canadian journalists used the series to promote dialogue and discussion about youth suicide issues. This is welcome news for public health advocates. Few public health issues have been solved with silence. On the contrary, positive media engagement with health issues can raise awareness, catalyze policy change and even affect individual health (and help-seeking) behaviours [46]. This is particularly the case when used in conjunction with other public health and health promotion strategies. For example, cigarette smoking and drunk driving have declined over the last decades following media engagement involving education, awareness and prevention $[47,48]$. Likewise, open discussion in families, schools and workplaces is the basis of many high-profile Canadian campaigns to reduce stigma associated with mental illness such as 'Bell Let's Talk' as well as the activities of the MHCC.

Articles reported that schools banned discussion of the series, and expressed serious concerns about its impact. The results suggest that more can be done to help schools and educators vis-à-vis best practice in suicide prevention, especially as a recent review indicated that commonly used programs were not effective, and sometimes even resulted in harm [49]. One approach, inspired by this study, could be the creation and distribution of evidence-based recommendations for teachers about how to talk about suicide and mental health with students. This may help reduce some of the confusion and ambivalence in Canadian schools regarding suicide prevention and mental health promotion.

There are some limitations to this study. Firstly, the study only included English-language Canadian newspapers. Newspapers in other jurisdictions or other languages may have given different results. Given the size and global influence of American media, a parallel study on U.S media may be an important next step, especially as this has recently been implicated in higher suicide rates following Robin Williams suicide [25]. Secondly, the study did not assess other forms of media such as television, radio, or social media, which may have given different results. Indeed, there is a pressing need for more research on the topic of social media and suicide, especially regarding its impact on young people. Thirdly, we collected three months of data. Although this provides a rigorous time-span of media coverage in the era of rapid news, new articles may have appeared since which were not included in our analysis. Fourthly, this paper is based on analysis of a fictional suicide, meaning that some of the 14 Mindset recommendations were not applicable. As such, the paper is inspired by Mindset, but is not a formal test of fidelity to all 14 recommendations, which would be better done through analysis of actual suicides.

\section{Conclusions}

This study suggests that Canadian newspapers generally adhered to core best practice recommendations on how to sensitively report on suicide when discussing 13 Reasons Why. The results also suggest that Canadian journalists tended to apply a critical lens in discussing the series and its implications for youth suicide and youth mental health. This involved praise and criticism in equal measure. These findings suggest that, taken in the round, the Canadian media is acting in a socially responsible manner consistent with best practice. This may have a positive effect on public beliefs, behaviours and attitudes regarding youth suicide and suicide prevention.

\section{Additional file}

Additional file 1: Table S1. The 14 Mindset Recommendations for Reporting Suicide (DOCX 16 kb) 


\section{Appendix}

Table 4 List of newspaper articles included in sample

A01 Harris, B. All the right reasons; With Selena Gomez producing, series was a no-brainer for Katherine Langford. Winnipeg Sun. 2 April 2017.

A02 Schneller, J. Plenty of good reasons why you should watch this gutsy adaptation. Metro News. 2 April 2017.

A03 Ali, L. 13 Reasons Why is Netflix's newest must-see series. The Daily Gleaner. 4 April 2017.

A04 Weidner, J. Suicide prevention experts worry about danger of show focused on teen's death. The Record. 24 April 2017.

A05 CBC News. '13 Reasons Why' criticized for messaging on teen suicide. CBC.CA News. 25 April 2017.

A06 CBC Radio's Ottawa Morning. Ottawa Catholic School Board leery of new Netflix series 13 Reasons Why. CBC.CA News. 25 April 2017. Whitehouse, B. Parents beware: Experts worry Netflix's '13 Reasons Why' might glamorize teen suicide. The Hamilton Spectator. 25 April 2017. Samba, M. Downtown Mission urges public to use Netflix series 13 Reasons Why as way to discuss mental health, suicide. Windsor Star. 25 April 2017. May, D. Ottawa Catholic School Board warns teachers about 13 Reasons Why. Metro News. 25 April 2017. Laframboise, K. Talk to teenagers about 13 Reasons Why, urge mental health professionals and parents. CBC.CA News. 26 April 2017. Toronto Star. 13 Reasons Why called "dangerous" for teens with depression. The Toronto Star. 26 April 2017. Hank, M. Trouble bonding? Try TV. Edmonton Journal. 27 April 2017. Warren, M. Ontario Ministry of Education warns boards not to use Netflix's 13 Reasons Why in classroom. Metro News. 27 April 2017. Markan, Z. Controversial show 13 Reasons Why resonates with psychologist's teen clients. CBC.CA News. 28 April 2017. Bellefontaine, M. Principal orders Edmonton students not to talk about 13 Reasons Why at school. CBC.CA News. 28 April 2017. Hamilton Spectator. Public school board warns parents about Netflix hit '13 Reasons Why'. The Hamilton Spectator. 28 April 2017. Hamilton Spectator. The Spectator's View: Reasons to talk about '13 Reasons Why'. The Hamilton Spectator. 28 April 2017. CBC News. Calgary Catholic schools nix Netflix series about teen suicide, 13 Reasons Why. CBC.CA News. 28 April 2017. Okeke, S. 'Let your kid watch it,' Quebec teen says of controversial 13 Reasons Why. CBC.CA News. 29 April 2017. Dimoff, A. B.C. schools warn of graphic content in Netflix series '13 Reasons Why'. CBC.CA News. 29 April 2017. Nathoo, Z. 13 Reasons Why: Is it 'exposing the truth' or a 'primer' on teen suicide? CBC.CA News. 29 April 2017. Li, W. Mental health experts emphasize suicide awareness in light of Netflix's 13 Reasons Why. Metro News. 30 April 2017. Edwardson, L. 'It could be a conversation starter': Calgary school board open to discussing 13 Reasons Why with students. Metro News. 30 April 2017. Picard, A. Yes, 13 Reasons Why glorifies suicide. You should watch - and talk to your kids. The Globe and Mail. 30 April 2017. Proceviat, S. Morning Update newsletter: Purdue OKs settlement; Home Capital future uncertain; Oilers lose; Also: Ontario takes chance on basic income; lumber producers take hit. The Globe and Mail. 1 May 2017.

Doyle, J. The fuss over 13 Reasons Why is absurd. The Globe and Mail. 1 May 2017. Hunter, A. Suicide prevention spurs Regina students to action. CBC.CA News. 2 May 2017. Mahmood, D. RE: "13 Reasons Why" warning. The Hamilton Spectator. 2 May 2017. Ahsan, S. Netflix adds trigger warnings to 13 Reasons Why after Canadian school board bans series for 'glamorizing' suicide. National Post. 2 May 2017. O'Loughlin, E. Opinion: 13 Reasons Why and suicide prevention. Montreal Gazette. 2 May 2017. Lalonde, M. Schools concerned Netflix series may trigger or glorify suicide. Montreal Gazette. 2 May 2017. Devlin, M. 13 Reasons Why's depiction of suicide sparks notes from capital region schools. Times Colonist. 2 May 2017. Masonic Temple to reopen as Concert Hall. Toronto Star. 3 May 2017. Ahsan, S. Netflix adds warnings to 13 Reasons Why. Montreal Gazette. 3 May 2017. Porter, J. Suicide prevention advocate sees opportunity in buzz around 13 Reasons Why. CBC.CA News. 3 May 2017. Kinsella, S. Don't work 13 Reasons Why into your lesson plan, NLESD tells teachers. CBC.CA News. 4 May 2017. Andrews, T. Netflix's '13 Reasons Why' gets more trigger warnings. The Hamilton Spectator. 4 May 2017. 
Table 4 List of newspaper articles included in sample (Continued)

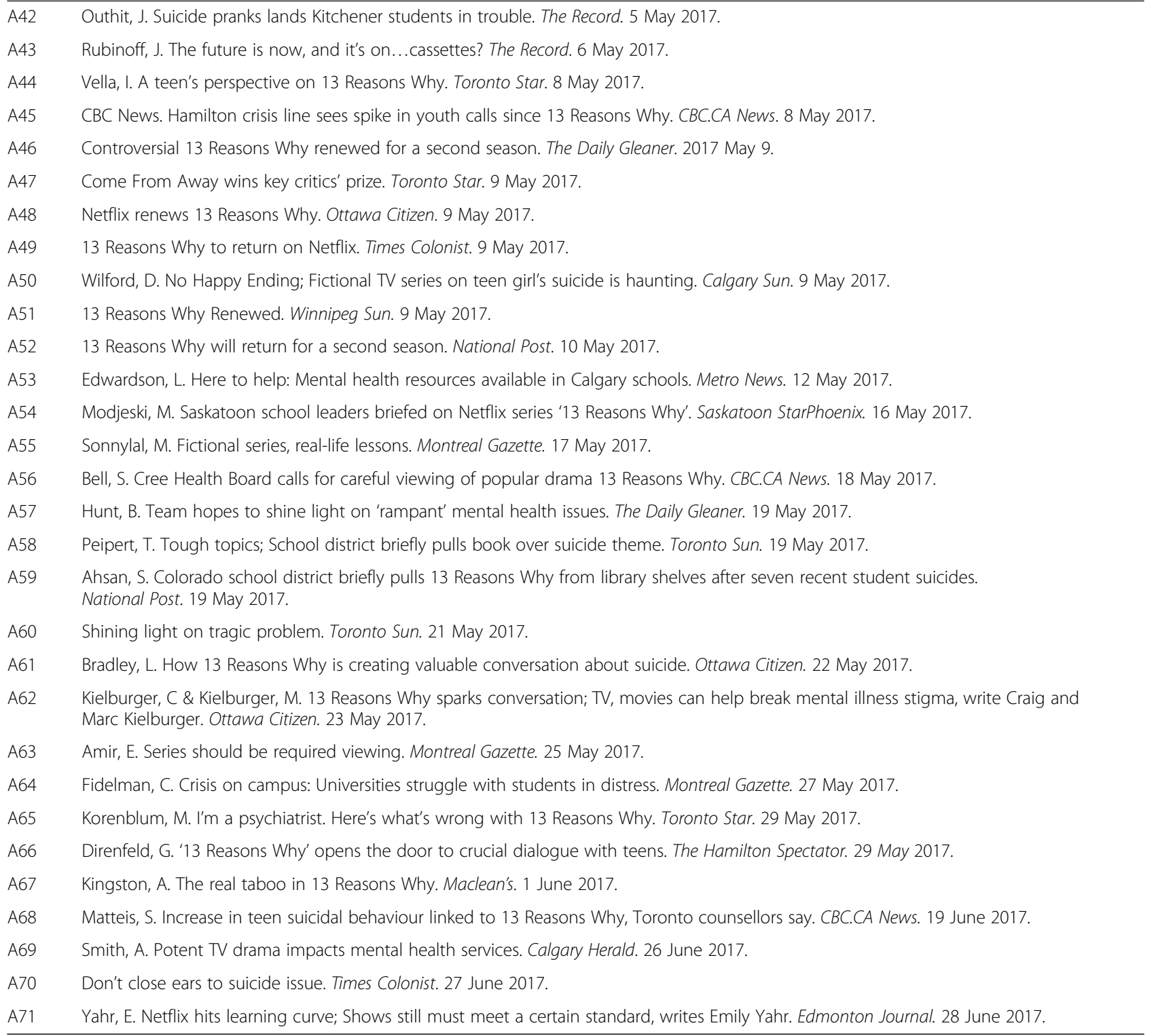

\section{Abbreviations}

MHCC: Mental Health Commission of Canada

\section{Funding}

The study was funded by the Mental Health Commission of Canada, which is funded by Health Canada.

\section{Availability of data and materials}

A list of all newspaper articles analyzed in this study are provided in the Appendix section of this published article.

\section{Authors' contributions}

VC conceptualized and designed the study, collected, analyzed and interpreted the data, and drafted the manuscript. RW oversaw data collection and analysis, and provided critical revisions to the manuscript. Both authors read and approved the final manuscript.

Ethics approval and consent to participate

Not applicable as no human subjects.

\section{Consent for publication}

Not applicable.

\section{Competing interests}

The authors declare that they have no competing interests.

\section{Publisher's Note}

Springer Nature remains neutral with regard to jurisdictional claims in published maps and institutional affiliations.

\section{Received: 9 March 2018 Accepted: 23 August 2018}

Published online: 31 August 2018

\section{References}

1. World Health Organization. World Health Statistics 2017: Monitoring Health for the SDGs, Sustainable Development Goals. Geneva: World Health Organization; 2017. 
2. Xu J, Murphy SL, Kochanek KD, Arias E. Mortality in the United States, 2015 Atlanta, GA: Centers for Disease Control and Prevention. NCHS Data Brief; 2016;(267):1-8

3. Australian Bureau of Statistics (ABS). Causes of death, Australia, 2016: Suicide in Australia. [internet]. 2017; [cited 2018 Feb 27]; ABS cat. no. 3303.0 Available from http://www.abs.gov.au.

4. Office for National Statistics. Statistical Bulletin: Suicides in the UK: 2016 registrations. [internet]. 2017; [cited 2018 Feb 27]. Available from https:// www.ons.gov.uk.

5. Navaneelan T. Suicide Rates: An Overview. Statistics Canada: Ottawa, ON: 2009.

6. Khan S. Aboriginal mental health: the statistical reality. Vis J. 2008;5(1):6-7.

7. Skinner R, McFaull S. Suicide among children and adolescents in Canada: trends and sex differences, 1980-2008. Can Med Assoc J. 2012;184(9):1029-34

8. Mental Health Commission of Canada. Changing directions, changing lives: The mental health strategy for Canada. Ottawa, ON: Mental Health Commission of Canada; 2012.

9. Anastasio PA, Rose KC, Chapman J. Can the media create public opinion? A social-identity approach. Psychol Med. 1999;8(5):152-5.

10. Humphries B. Comparing "insider" and "outsider" news coverage of the 2014 Ebola outbreak. Can J Public Health. 2017;108(4):E381-7.

11. Wilson K, Code C, Dornan C, Ahmad N, Hébert P, Graham I. The reporting of theoretical health risks by the media: Canadian newspaper reporting of potential blood transmission of Creutzfeldt-Jakob disease. BMC Public Health. 2004;4(1):1.

12. Holmes BJ. Media coverage of Canada's obesity epidemic: illustrating the subtleties of surveillance medicine. Crit Public Health. 2009;19(2):223-33.

13. Rock M. Diabetes portrayals in north American print media: a qualitative and quantitative analysis. Am J Public Health. 2005;95(10):1832-8.

14. Dreser A, Vázquez-Vélez E, Treviño S, Wirtz VJ. Regulation of antibiotic sales in Mexico: an analysis of printed media coverage and stakeholder participation. BMC Public Health. 2012;12(1):1051.

15. McWhirter JE, Hoffman-Goetz L. Skin deep: coverage of skin cancer and recreational tanning in Canadian women's magazines (2000-2012). Can J Public Health. 2015;106(4):236-43.

16. Breheny $M$, Severinsen $C$. Is social isolation a public health issue? A media analysis in Aotearoa/New Zealand. Crit Public Health. 2017;10:1-10.

17. McGinty EE, Webster DW, Jarlenski M, Barry CL. News media framing of serious mental illness and gun violence in the United States, 1997-2012. Am J Public Health. 2014;104(3):406-13.

18. Whitley R, Berry S. Trends in newspaper coverage of mental illness in Canada: 2005-2010. Can J Psychiatr. 2013;58(2):107-12.

19. Whitley R, Wang J. Good news? A longitudinal analysis of newspaper portrayals of mental illness in Canada 2005 to 2015. Can J Psychiatr. 2017:62(4):278-85.

20. Creed M, Whitley R. Assessing fidelity to suicide reporting recommendations in Canadian news media: the death of Robin Williams. Can J Psychiatr. 2017;62(5):313-7.

21. Gould MS, Wallenstein S, Davidson L. Suicide clusters: a critical review. Suicide Life-Threat Behav. 1989;19(1):17-29.

22. Stack S. Media impacts on suicide: a quantitative review of 293 findings. Soc Sci Q. 2000;81:957-71.

23. Gould MS. Suicide and the media. Ann N Y Acad Sci. 2001:932(1):200-24.

24. Stack S. Media coverage as a risk factor in suicide. J Epidemiol Community Health. 2003;57(4):238-40.

25. Fink DS, Santaella-Tenorio J, Keyes KM. Increase in suicides the months after the death of Robin Williams in the US. PLoS One. 2018;13(2):e0191405.

26. Cheng AT, Hawton $\mathrm{K}$, Lee $\mathrm{CT}$, Chen $\mathrm{TH}$. The influence of media reporting of the suicide of a celebrity on suicide rates: a population-based study. Int J Epidemiol. 2007:36(6):1229-34

27. Gould MS, Jamieson P, Romer D. Media contagion and suicide among the young. Am Behav Sci. 2003:46(9):1269-84.

28. The Canadian Journalism Forum on Violence and Trauma. Mindset: Reporting on mental health. 2nd ed. London, ON: The Canadian Journalism Forum on Violence and Trauma; 2017.

29. Netflix. 2017 on Netflix - A year in bingeing. Los Gatos, CA: Netflix; 2017.

30. Ayers JW, Althouse BM, Leas EC, Dredze M, Allem JP. Internet searches for suicide following the release of 13 reasons why. JAMA Intern Med. 2017;177(10):1527-9.
31. Infomart. About Infomart. https://www.infomart.com/about-infomart/. Accessed 14 June 2018.

32. FP Infomart takes social media research to new heights by teaming up with social media group. Financial Post. Toronto. [Internet]. N.d. Available from: http://business.financialpost.com/fpinfomart-takes-social-mediaresearch-tonew-heights-by-teaming-up-with-social-media-group.

33. Tricco AC, Duval B, De Serres G, Gilca V, Vrbova L, Anonychuk A, Krahn M. Moher D. A review of interventions triggered by hepatitis a infected foodhandlers in Canada. BMC Health Serv Res. 2006;6(1):157.

34. King L, Tulandi T, Whitley R, Constantinescu T, Ells C, Zelkowitz P. What's the message? A content analysis of newspaper articles about assisted reproductive technology from 2005 to 2011. Hum Fertil. 2014;17(2):124-32.

35. Barnetson B, Foster J. If it bleeds, it leads: the construction of workplace injury in Canadian newspapers, 2009-2014. Int J Occup Environ Health. 2015:21(3):258-65.

36. Newspapers Canada. Daily newspaper circulation report 2015. News Media Canada: Toronto, ON; 2016.

37. Rosenberg H, Feldman CS. No time to think: the menace of media speed and the 24-hour news cycle. New York: Continuum International; 2008.

38. Napoli P. Audience Evolution: New technologies and the transformation of media audiences. New York: Columbia University Press; 2011.

39. Shoemaker, PJ. 2006. "News and newsworthiness: a commentary." Communications 2006 31: 105-112.

40. Braun V, Clarke V. Using thematic analysis in psychology. Qual Res Psychol. 2006;3(2):77-101.

41. Miles MB, Huberman M. Qualitative data analysis. Thousand Oaks: Sage Publications; 1994

42. Whitley R, Crawford M. Qualitative research in psychiatry. Can J Psychiatr. 2005;50(2):108-14

43. Bajaj P, Borreani E, Ghosh P, Methuen C, Patel M, Joseph M. Screening for suicidal thoughts in primary care: the views of patients and general practitioners. Ment Health Fam Med. 2008:5(4):229.

44. Dazzi T, Gribble R, Wessely S, Fear NT. Does asking about suicide and related behaviours induce suicidal ideation? What is the evidence? Psychol Med. 2014:44(16):3361-3.

45. Luxton DD, June JD, Fairall JM. Social media and suicide: a public health perspective. Am J Public Health. 2012;102(S2):S195-200.

46. Wakefield MA, Loken B, Hornik RC. Use of mass media campaigns to change health behaviour. Lancet. 2010;376(9748):1261-71.

47. Durkin S, Brennan E, Wakefield M. Mass media campaigns to promote smoking cessation among adults: an integrative review. Tob Control. 2012:21(2):127-38

48. Elder RW, Shults RA, Sleet DA, Nichols JL, Thompson RS, Rajab W. Effectiveness of mass media campaigns for reducing drinking and driving and alcohol-involved crashes: a systematic review. Am J Prev Med. 2004:27(1):57-65.

49. Kutcher S, Wei Y, Behzadi P. School-and community-based youth suicide prevention interventions: hot idea, hot air, or sham? Can J Psychiatr. 2017;62(6):381-7.

\section{Ready to submit your research? Choose BMC and benefit from:}

- fast, convenient online submission

- thorough peer review by experienced researchers in your field

- rapid publication on acceptance

- support for research data, including large and complex data types

- gold Open Access which fosters wider collaboration and increased citations

- maximum visibility for your research: over $100 \mathrm{M}$ website views per year

At $\mathrm{BMC}$, research is always in progress.

Learn more biomedcentral.com/submission 